\title{
Significant Factors in Using Contracepties among Married Women in Cagayan de Oro City using Binary Logistic Regression
}

\author{
Jessyl D. Orlanes and Kennet G. Cuarteros
}

\begin{abstract}
Family planning is a larger concept involving preparation and knowledge around a "family future". It allows people to attain their desired number of children and determine the spacing of pregnancies, reduces the need for abortion, especially unsafe abortion. On the other hand, contraceptives are the group of methods you use or steps you take to avoid pregnancy before you are ready. Contraceptives, one of the methods of family planning, helps prevent the transmission of other sexually transmitted infections. Moreover, it can help slow down population growth thereby contributing to economic benefits such as poverty reduction. It is also a very helpful way to improve the health of mothers and childrens through birth spacing and avoiding high risk pregnancies. In this study, significant factors in using contraceptives are determined. Based on the results from the conducted survey, three out of ten variables were considered as significant factors namely: desire of having more children, religion, and employment status (having p-values of $0.005,0.008$, and 0.000 respectively). These significant factors were used in formulating the model to predict the probability of using contraceptives among married women. Using Hosmer and Lemeshow Test of goodness-of-fit, the p-value of the model is 0.728 . Thus, the model is a good fit. A re-survey was conducted to validate the model and $88 \%$ of the married women were correctly classified. Hence, the model will be very useful in predicting the probability of contraceptive use among married women.
\end{abstract}

Keywords: family planning, contraceptive, factors, binary logistic regression, model

Jessyl D. Orlanes has a Bachelor of Science degree in Applied Mathematics from the University of Science and Technology in Southern Philippines.

Kennet G. Cuarteros is an Associate Professor II in the Department of Applied Mathematics, University of Science and Technology in Southern Philippines. A recent publication includes: Classifying Student's Engagement in Computer Games using Linear Discriminant Analysis. 


\section{Introduction}

\section{Background of the Study}

Using contraceptives is the expression of human desire to space or limit birth. By practicing family planning, couples can improve the health of mothers and children through birth spacing and avoiding high risk pregnancies. Also, family planning can help slow down the population growth, thereby contributing to economic benefits such as poverty reduction.

In the Philippines, contraceptives are available for people from all kinds of lifestyles and all kinds of life plans. Whether you are single or married, whether you never want to have children or you want to have children come next year, individuals have their options. There are also a number of different contraceptive methods avaialable to them. Based on the results of the 2011 Family Health Survey of Philippine Statistics Authority (PSA), married women used the following contraceptive methods: female sterilization, pills, IUD, injectables, standard days method, lactational amenorrhea method, calendar/rhythm/periodic astinence, and other methods.

In the five decades since the birth control pill was created for the first time in the United States of America, the number of contraceptive products available for women has increased considerably. These numerous innovations were adaptations of current technologies which offer variations per hormone doses rather than real technological discoveries. At the same time, there was a current issue related to the high rate of unwanted pregnancies in the United States and in the entire world. (NICULESCU Gabriela)

Levels of contraceptive use provide the most obvious and widely accepted criterion of success with a family planning program. Since most women have tried at least one method, practical problems with particular methods, or in obtaining supplies may be important obstacles to further program advances. More than half of currently married women of reproductive age (55\%) in the Philippines are using a method of contraception. Data from the National Demographic Health Survey (NDHS) conducted in the Philippines indicates an increase of $6 \%$ in the use of contraceptives, from $49 \%$ of married women in 2003 to $55 \%$ in 2013 . The three most popular modern methods used by married women, as of 2013, are the pill (19\%), female sterilization (9\%), and injectibles and IUD at $4 \%$ each. Eighteen percent of married women have an unmet need for family planning, $7 \%$ because they want to delay their next pregnancy, and $11 \%$ because they do not want any more children.

Many factors can be associated with contraceptive use. Reasons for Using Contraception: Perspectives of U.S. Women Seeking Care at Specialized Family Planning Clinics (2013), by Jennifer Frost and Laura Lindberg of the Guttmacher Institute, indicated that the researchers interviewed more than 2,000 women across the United States. Results showed that women in the U.S. use contraception because it allowed them to plan their lives. Most participants said that contraception has allowed them to take better care of themselves or their families (63\%), support themselves financially (56\%), complete their education (51\%), or keep or get a job (50\%). Women also said that an unintended pregnancy could have negative consequences on their lives and those of their families. Women with children said that being able to take care of their children was a 
reason to use contraception. Other factors that can affect the use of contraceptives may be related to their religion, age, educational attainment, economic status, residency, their desire of have children, and the media's influence through televisions and newspapers.

The development of, and increased access to, modern contraception has been heralded by the U.S. Centers for Disease Control and Prevention (CDC) as one of the ten greatest public health achievements of the 20th century. In 2011, the U.S. Department of Health and Human Services adopted guidelines specifying that contraceptive services should be included as basic preventive care for women. In documenting the important role of family planning, research has emphasized the links between contraceptive use and the later ages at marriage, smaller families, longer birth intervals, and the ability of women and couples to plan when and how many children to bear (Frost and Lindberg, 2013).

From Philippine Statistics Authority's data, the population of Cagayan de Oro City has grown from 461,877 in 2000 to 675,950 in 2015. As of 2015, $16.5 \%$ of Filipino families were poor, and $8.1 \%$ were not able to meet their basic food need. In order to reduce the population growth rate, as well as the risk of women and children and the poverty level of the society, contraceptives methods have been used as an effective measure in family planning all over the world. Family planning service can reduce unwanted pregnancies, injury, illness and death associated with child birth, and abortions. In relation to this, it is important to determine the significant factors in using contraceptives among married women.

\section{Statement of the Problem}

The latest statistical data of population growth according to Phillipine Statistics Authority (2015 Census of Population), Cagayan de Oro City's population growth rate from the year 2000 2010 is $2.69,2010-2015$ is 2.23 , and $2000-2015$ is 2.53 . This means that the population will grow more in the years to come. One implication for overpopulation is that it causes an insufficiency of the limited resources that are avaialable. This is currently affecting the poorer population in the city. Overpopulation also reduces the ability of people in power to regulate events due to the difficulty of tracking the movement of people (e.g. following the spread of diseases) and controlling increasing crime rates. In association with this, it is important to have a plan that will help lessen population growth and prevent negative events from occurring. The use of contraceptives is a possible solution to minimizing population growth. This study seeks to determine the significant factors influencing contraceptive use among married women aged 25 49 years in Cagayan de Oro City since the data of the National Demographic Health Survey (NDHS) conducted in the Philippines shows only an increase of 6\% in the use of contraceptives, from 49 percent of married women in 2003 to $55 \%$ in 2013.

\section{Objectives of the Study}

This research aims to determine the significant factors in using contraceptives among married women in Cagayan de Oro City using Binary Logistic Regression. Specifically, the objectives of the study are as follows: 
1. Determine the significant factors related to Contraceptive use among married women aged 25-49 years in Cagayan de Oro using binary logistric regression.

2. Formulate a predictor model using Binary Logistic Regression.

3. Evaluate the resulting model.

4. Validate the model.

Scope and Limitations of the Study

The study focused on the ten most populated barangay in Cagayan de Oro City, (namely: Carmen, Camaman-an, Kauswagan, Bugo, Iponan, Gusa, Lapasan, Balulang, Bulua, Macasandig) getting a sample of 15 married women aged 25 - 49 years old in each barangay. The data were acquired through a survey questionnaire.

\section{Significance of the Study}

By identifying the significant factors that have the most impact related to contraceptive use, the local government will be able to discover the factors where more emphasis should be placed with regard to family planning. And also, they will determine the actions that need to be performed in order to spread the usefulness of contraceptives/family planning in the City's population and provide important guidelines for improving family planning services. Moreover, this study will serve as a guide for future researchers that aims to develop the impact of contraceptive use/family planning on the community.

\section{Basic Concepts and Methodology}

\section{Basic Concepts}

Regression analysis is a predictive modelling technique which investigates the relationship between a dependent variable (target) and independent variable(s) (predictor). This technique is used for forecasting, time series modelling, and finding the causal effect relationship between variables. There are multiple benefits of using regression analysis. They are as follows:

1. It indicates the significant relationships between dependent variable and independent variable.

2. It indicates the strength of impact of multiple independent variables on a dependent variable. 
Regression analysis also allows us to compare the effects of variables measured on different scales.

Logistic regression is used to find the probability of event=Success and event=Failure. We should use logistic regression when the dependent variable is binary (0/ 1, True/ False, Yes/ No) in nature. Here the value of $\mathrm{Y}$ ranges from 0 to 1 and it can represented by the following equation.

$$
\begin{aligned}
& \text { odds }=p /(1-p)=\text { probability of event occurrence } / \text { probability of not event occurrence } \\
& \ln (\text { odds })=\ln (p /(1-p)) \\
& \operatorname{logit}(p)=\ln (p /(1-p))=b 0+b 1 X 1+b 2 X 2+b 3 X 3 \ldots .+b k X k
\end{aligned}
$$

Since we are working here with a binomial distribution (dependent variable), we need to choose a link function which is best suited for this distribution. Moreover, it is a logit function. In the equation above, the parameters are chosen to maximize the likelihood of observing the sample values rather than minimizing the sum of squared errors (like in ordinary regression).

- Logistic regression does not require a linear relationship between the dependent and independent variables. It can handle various types of relationships because it applies a non-linear log transformation to the predicted odds ratio. It requires large sample sizes because maximum likelihood estimates are less powerful at low sample sizes compared to ordinary least square.

\section{Binary Logistic Regression}

Binary logistic regression is used to analyze binary outcome variables. It also makes use of the relationship between independent variables and a discrete dependent variable (or outcome). This model can be used to examine the effect of a particular exposure on an outcome variable including:

(1) Comparing the level of an outcome variable in two exposure groups

(2) Comparing more than two exposure groups, through the use of indicator variables to estimate the effect of different levels of a categorical variable, comparing to a baseline.

The outcome in logistic regression analysis is often coded as 0 and 1 , where 1 indicates that the outcome of interest is present, and 0 indicates that the outcome of interest is absent. If we define $\mathrm{p}$ as the probability that the outcome is 1 , the multiple logistic regression model can be written as follows:

$$
\pi=\frac{e^{\left(b_{0}+b_{1} X_{1}+b_{2} X_{2}+\cdots+b_{p} X_{p}\right)}}{1+e^{\left(b_{0}+b_{1} X_{1}+b_{2} X_{2}+\cdots+b_{p} X_{p}\right)}}
$$


where $\pi$ : is the expected probability that the outcome is present;

$\mathrm{X}_{1}$ through $\mathrm{X}_{\mathrm{p}}$ : are distinct independent variables; and

$b_{0}$ through $b_{p}$ : are the estimated coefficients.

\section{Assumptions for Binary Logistic Regression}

There are three major assumptions of binary logistic regression. These are:

1. The outcome must be discrete, otherwise explained as, the dependent variable should be dichotomous in nature (e.g., presence vs. absent);

2. There should be no outliers in the data, which can be assessed by converting the continuous predictors to standardized, or $\mathrm{z}$ scores, and remove values below -3.29 or greater than 3.29;

3. There should be no high intercorrelations (multicollinearity) among the predictors. This can be assessed by a correlation matrix among the predictors. Tabachnick and Fidell (2012) suggest that as long correlation coefficients among independent variables are less than 0.90 the assumption is met.

Since the outcome of this study is binary or dichotomous ( 1 for using contraceptives, 0 otherwise), assumption 1 was met. It has no outliers independent variables, hence assumption 2 was satisfied. Assumption 3 was evaluated by looking at the correlation matrix among the independent variables before analyzing them using logistic regression.

Table 1: Correlation Matrix among Independent Variables

\begin{tabular}{|r|c|c|c|c|c|c|c|c|c|c|}
\hline & Desire & Education & Religion & Work & Income & Radio & TV & Newspaper & ZAge & ZChildren \\
\hline Desire & 1.000 & .345 & -.232 & .311 & .264 & .197 & -.236 & -.049 & -.181 & .025 \\
Education & .345 & 1.000 & -.056 & .246 & .197 & .400 & -.363 & -.361 & .011 & .059 \\
Religion & -.232 & -.056 & 1.000 & -.251 & .278 & -.062 & .369 & -.559 & -.101 & -.166 \\
Work & .311 & .246 & -.251 & 1.000 & .280 & -.118 & .089 & .121 & -.139 & .271 \\
Income & .264 & .197 & .278 & .280 & 1.000 & .057 & .192 & -.665 & -.064 & .050 \\
Radio & .197 & .400 & -.062 & -.118 & .057 & 1.000 & -.555 & -.432 & -.079 & -.180 \\
TV & -.236 & -.363 & .369 & .089 & .192 & -.555 & 1.000 & -.120 & -.006 & -.107
\end{tabular}




\begin{tabular}{|r|c|c|c|c|c|c|c|c|c|c|} 
Newspaper & -.049 & -.361 & -.559 & .121 & -.665 & -.432 & -.120 & 1.000 & -.045 & .168 \\
ZAge & -.181 & .011 & -.101 & -.139 & -.064 & -.079 & -.006 & -.045 & 1.000 & -.269 \\
ZChildren & .025 & .059 & -.166 & .271 & .050 & -.180 & -.107 & .168 & -.269 & 1.000 \\
\hline
\end{tabular}

In Table 1, the correlation matrix showed the intercorrelations among the 10 variables. None of the correlations is greater than 0.90 . Thus, assumption 3 was satisfied.

\section{Methodology}

\section{Gathering the Data}

The data were acquired through a survey questionaire. It was a household-based survey with a sample of 15 married women aged 25-49 years old from each of the top ten populous barangay in Cagayan de Oro City.

\section{Determining the Significant Factors}

Using a statistical software, the significant factors were calculated using an Enter method. The enter method is a technique for variable selection that involves including all variables at a single step and thus, there was no exclusion involved. It was also used in this study since this method is usually applied in other researches involving binary logistic regression.

The test calculated p-values of each variable. Those variables which have p-values of less than 0.05 were considered significant. Through this, the proposed logistic regression model was formulated.

\section{Formulate a Predictor Model}

A predictor model was formulated using Binary Logistic Regression after determining the significant factors in using contraception. 


\section{Evaluation of the Model}

The Hosmer-Lemeshow test, a test of goodness-of-fit of the model, was employed. This is one of the statistical measures that tell how good the model is based on its significance measure.

\section{Validation of the Model}

A re-survey was conducted to validate the formulated model. The data were fitted to the model and the results were compared to the actual observations.

\section{Results}

This section presents the findings, analysis, and interpretation of the data that was gathered. The main objective was to determine the significant factors in using contraceptives among married women. The first part presented the data obtained from the survey, its descriptive statistics, and the result of the statistical software, where it shows the significant factors. The second part was the formulation of the predicting model. The third part was the evaluation of the model. The fourth part was the validation of the formulated predicting model.

\section{Determining the Significant Factors that Affects Contraceptive Use}

The response variable included in this study is contraceptive use or non-use. Hence, the response variable $Y_{i}$ for ith woman can be expressed as: 1, those women who were using a contraceptive method and 0 , those who were not using a contraceptive method. The independent variables were the desire of having more children, educational attainment, religion, employment status, family income per month, heard family planning on radio, heard family planning on television, read family planning on newspaper, age, and number of children. The list of variables with their respective unit of measurement is shown in Table 2. 


\section{Table 2: Variable Information}

\begin{tabular}{|c|c|}
\hline \multicolumn{2}{|l|}{ Using of Contraceptives } \\
\hline Dependent Variable & Codes \\
\hline Respondents $\left(Y_{i}\right)$ & 1: yes, $0:$ no \\
\hline Independent Variables & Codes \\
\hline$\left(X_{1}\right)$ Desire of having more children & 1: yes, $0:$ no \\
\hline$\left(X_{2}\right)$ Educational Attainment & $\begin{array}{l}\text { 2: College, 1: High School, } \\
\text { 0: Elementary }\end{array}$ \\
\hline$\left(X_{3}\right)$ Religion & $\begin{array}{l}\text { 3: Others, 2: Muslim, 1: Protestant, } \\
\text { 0: Catholic }\end{array}$ \\
\hline$\left(X_{4}\right)$ Employment Status & 1: yes, $0:$ no \\
\hline$\left(X_{5}\right)$ Family income per month & $\begin{array}{l}\text { 3: Between P31,560 to } 78,900 \text {, } \\
\text { 2: Between P } 15,780 \text { to } 31,560 \text {, } \\
\text { 1: Between P } 7,890 \text { to } 15,780 \text {, }\end{array}$ \\
\hline$\left(X_{6}\right)$ Heard family planning on Radio? & 1: yes, $0:$ no \\
\hline$\left(X_{7}\right)$ Heard family planning on Television? & 1: yes, $0:$ no \\
\hline$\left(X_{8}\right)$ Read family planning from Newspaper? & 1: yes, $0:$ no \\
\hline$\left(X_{9}\right)$ Age & - \\
\hline$\left(X_{10}\right)$ Number of Children & - \\
\hline
\end{tabular}




\section{Descriptive Statistics of the Factors}

The data obtained from the survey is presented below in bar graphs. This illustrates the number of married women in using and not using contraceptives that corresponds to each factor.

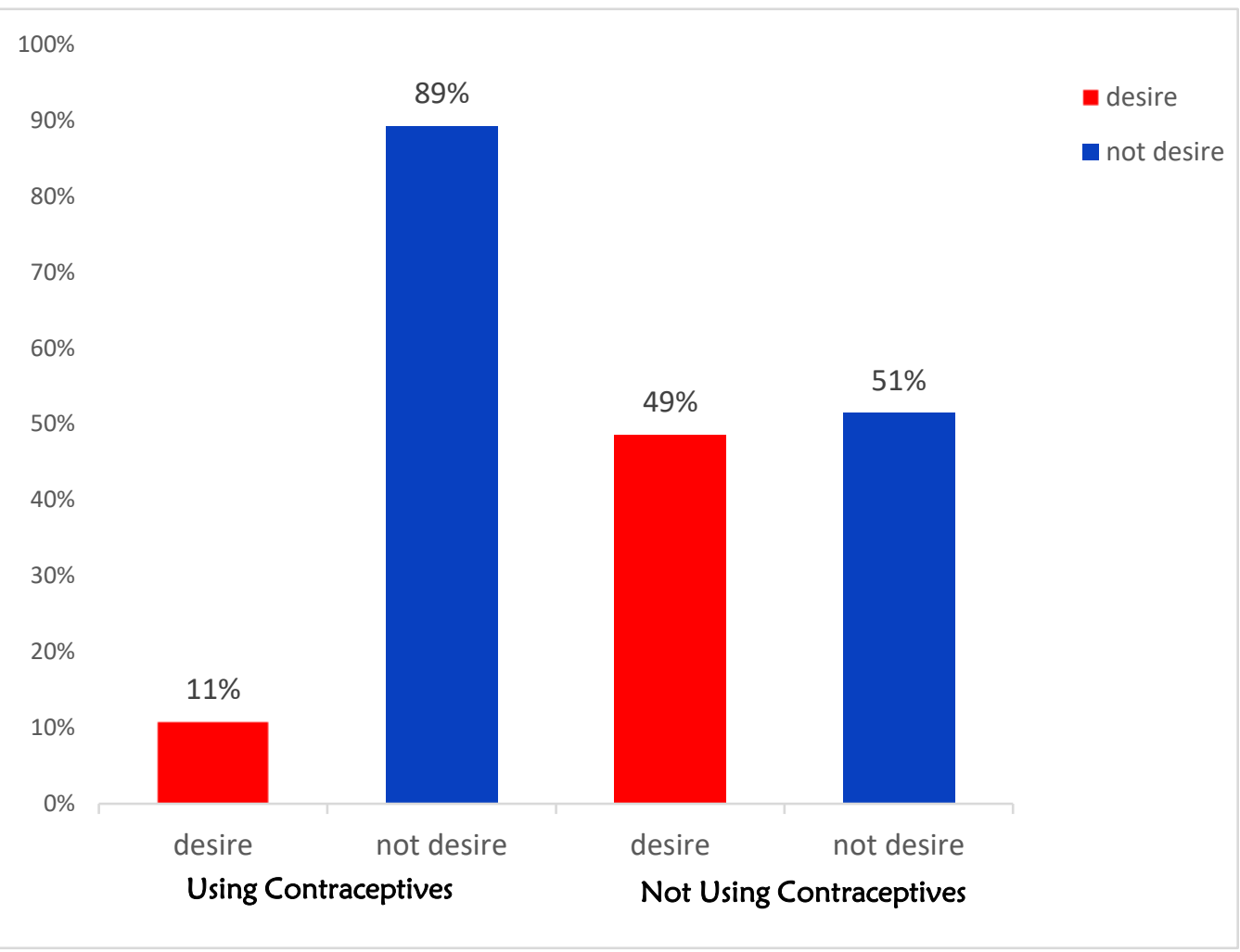

Figure 1. Married Women's Desire to Have More Children.

The majority of women that do not desire more children used contraceptives, while married women who were not using contraceptives desired to have more children almost had the same percentage as compared to those married women that were not desirous of having more children. 


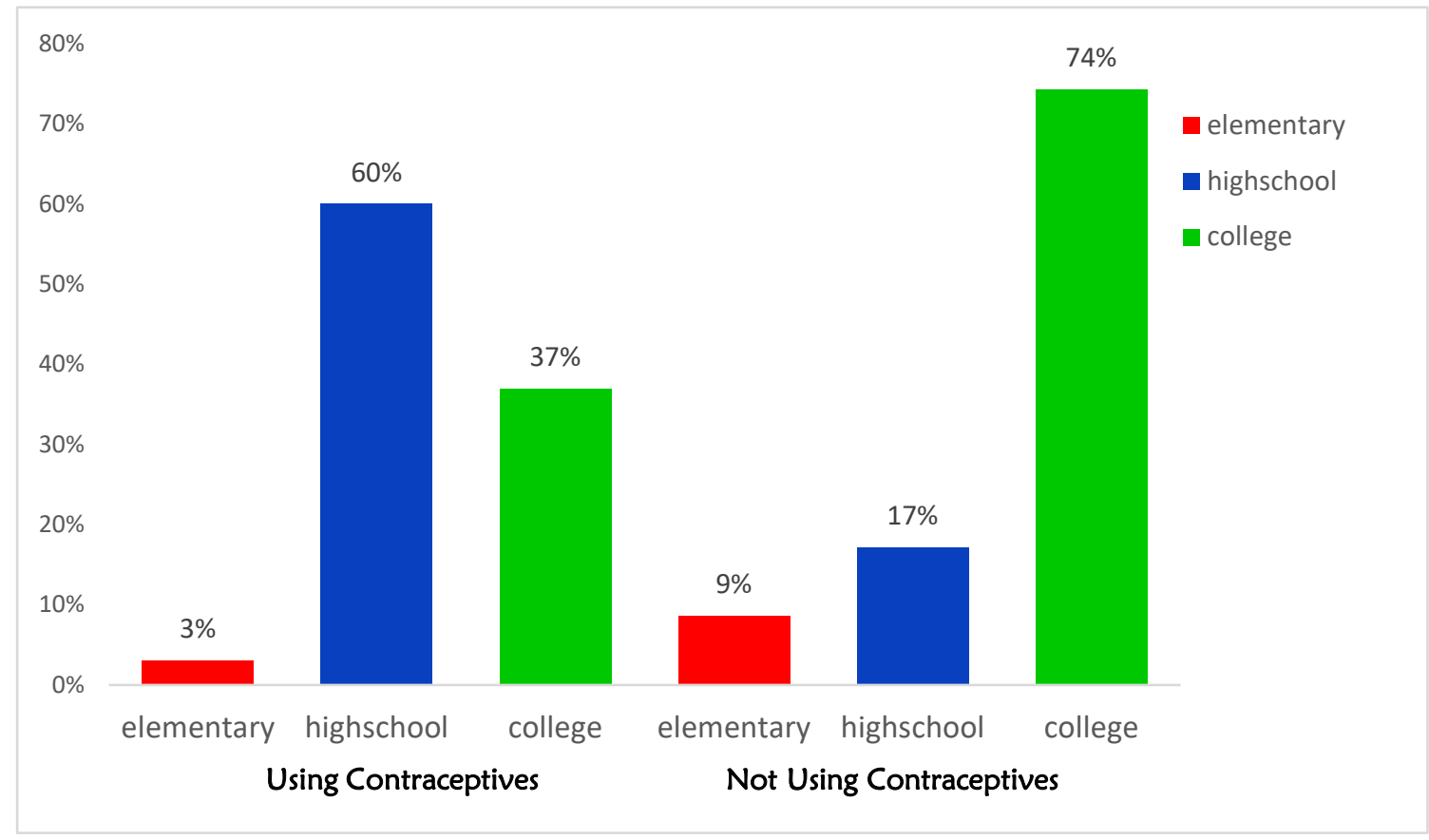

Figure 2. Married Women's Educational Attainment.

In regard to the level of education, the majority of married women that were using contraceptives have a secondary level of education. Seventy-four percent of married women who were in college/university were not using contraceptives, while $37 \%$ were using contraceptives. 


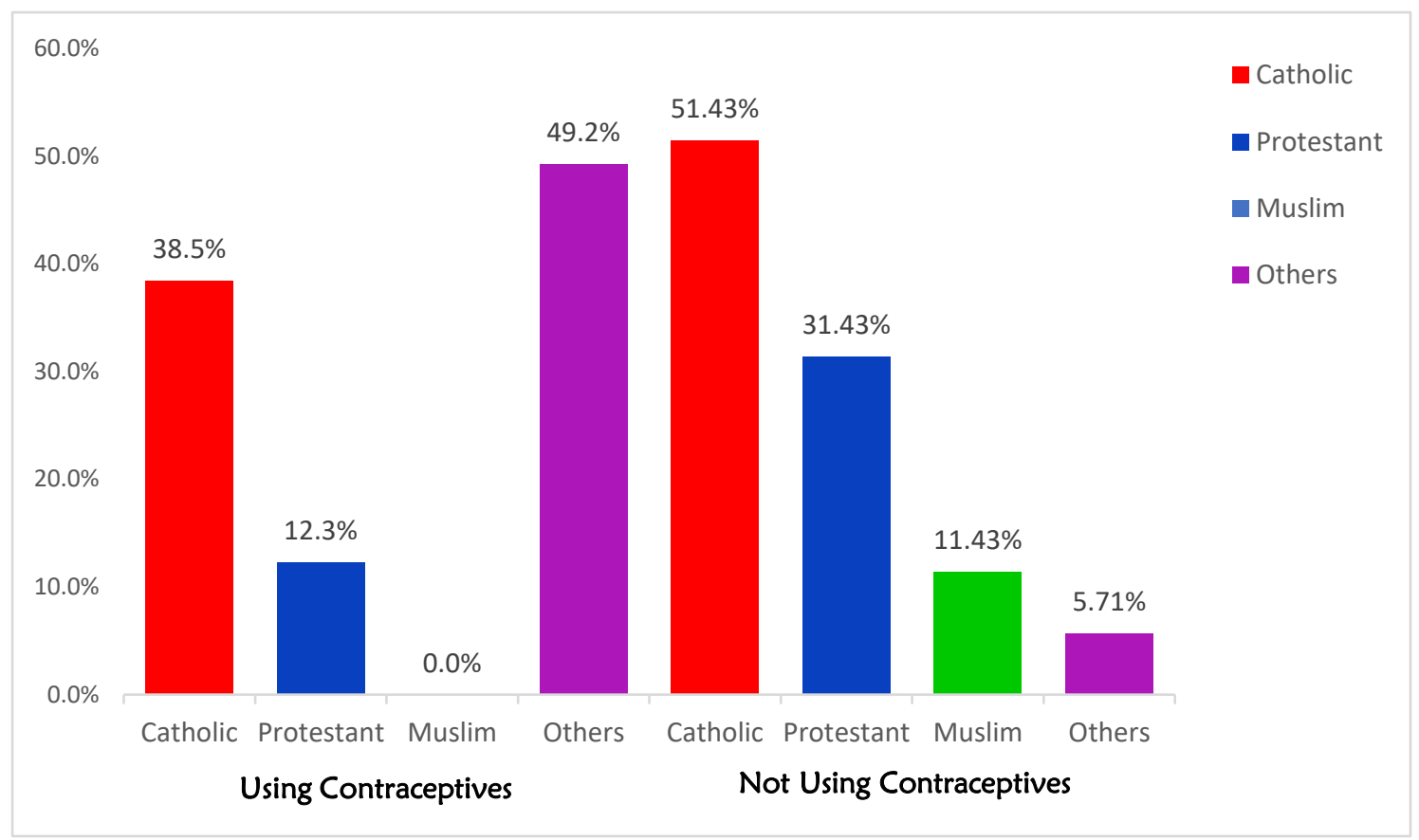

Figure 3. Married Women's Religion

$38.5 \%, 12.3 \%, 0.0 \%$, and $49.2 \%$ of married women who belong to Catholic, Protestant, Muslim, and other religion, respectively, were using contraceptives. The majority of married women who followed the Catholic faith were not using contraceptives. 


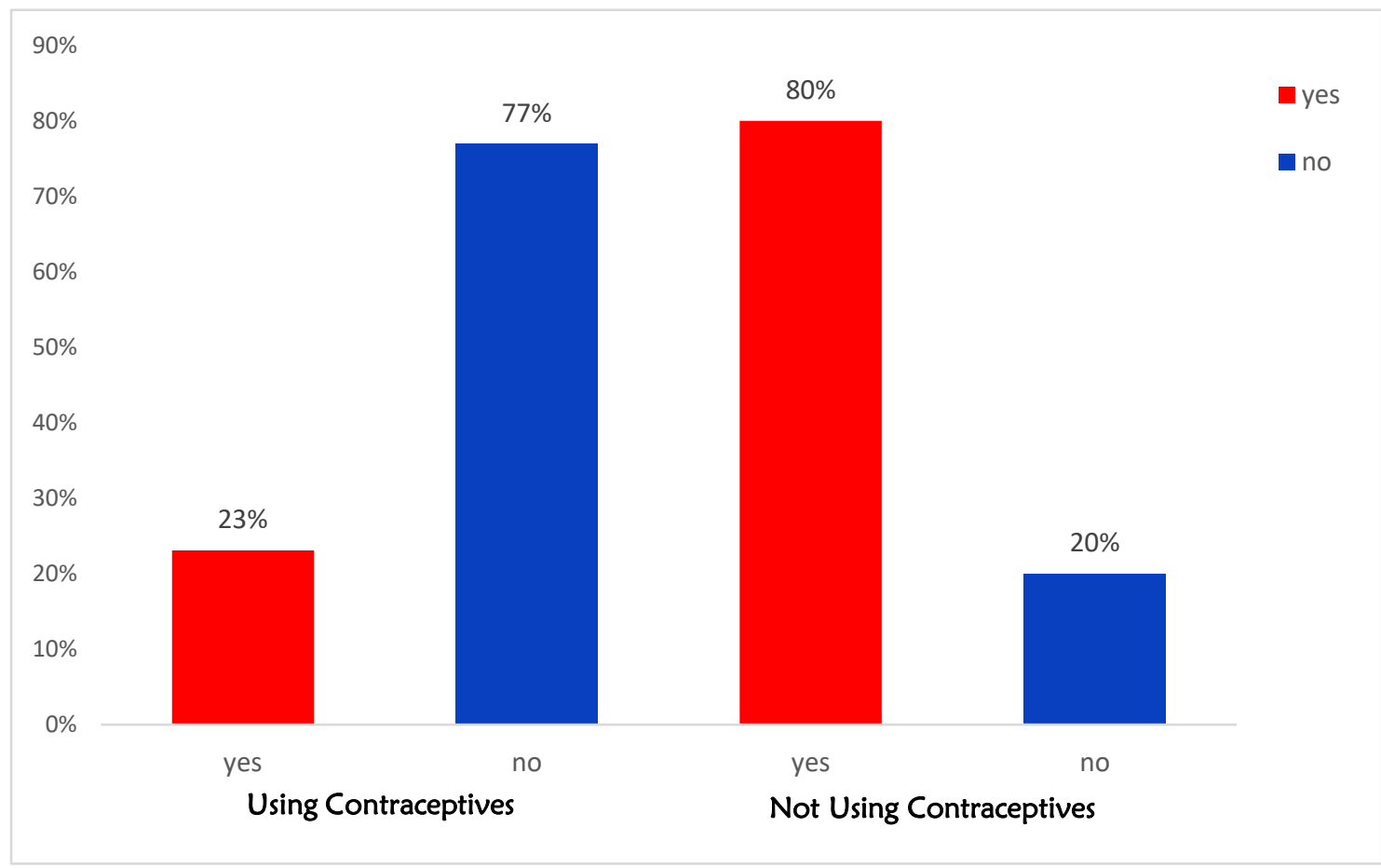

Figure 4. Married Women's Employment Status.

Seventy-seven percent of married women who used contraceptives did not work, while $23 \%$ were employed. Also, $80 \%$ who were employed were not using contraceptives, while $20 \%$ of married women who were not using contraceptives were unemployed. 


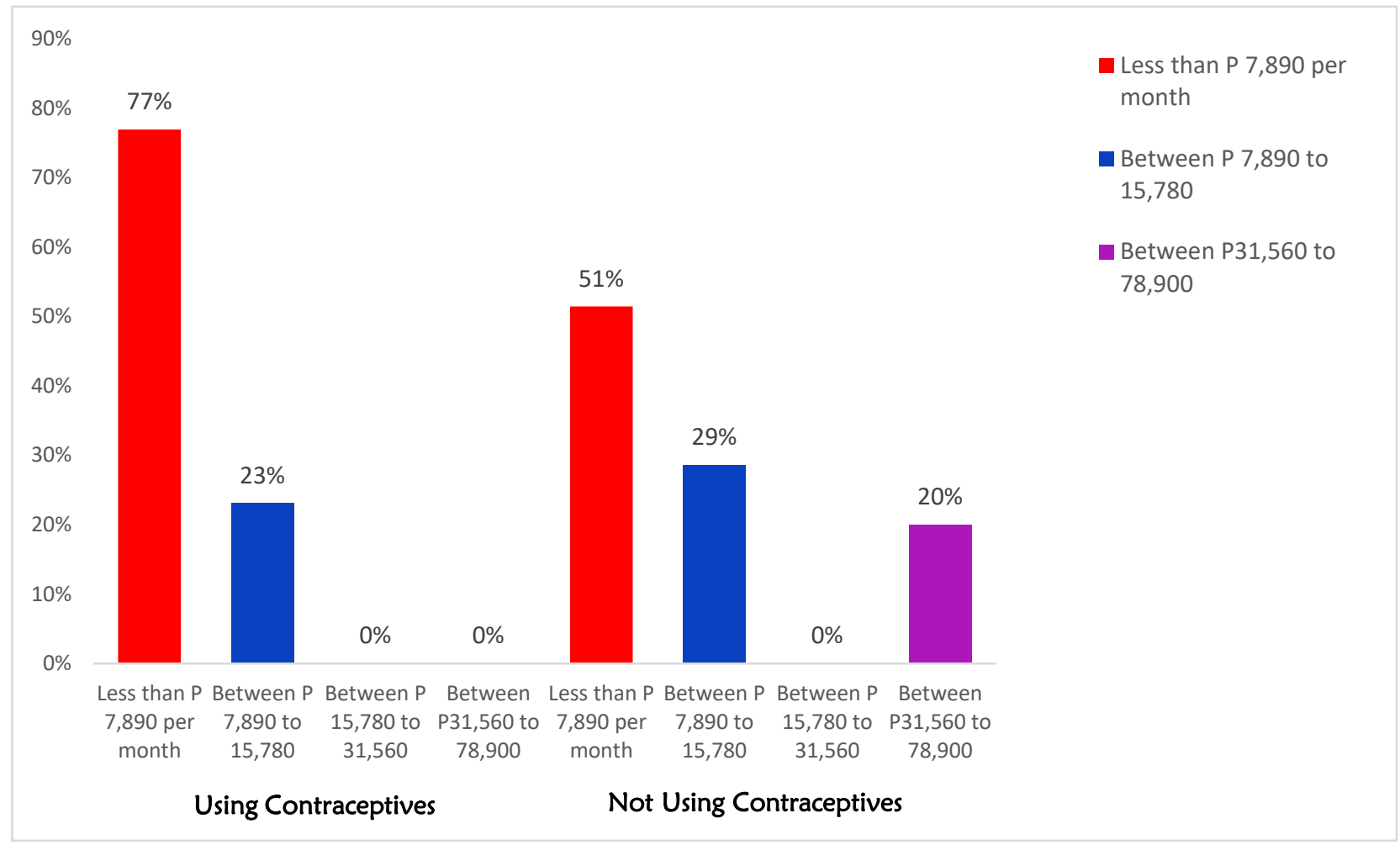

Figure 5. Married Women's Family Income per Month.

The majority of married women that were using contraceptives had a family income of less than P 7, 890 per month, while $23 \%$ of them had a family income between P 7, 890- P 15 , 780. On the other hand, $51 \%$ of married women who were not using contraceptives had a family income of less than P 7, 890 per month, $29 \%$ had a family income between P 7,890 to 15,780, and $20 \%$ had a family income between P31,560 to 78,900. 


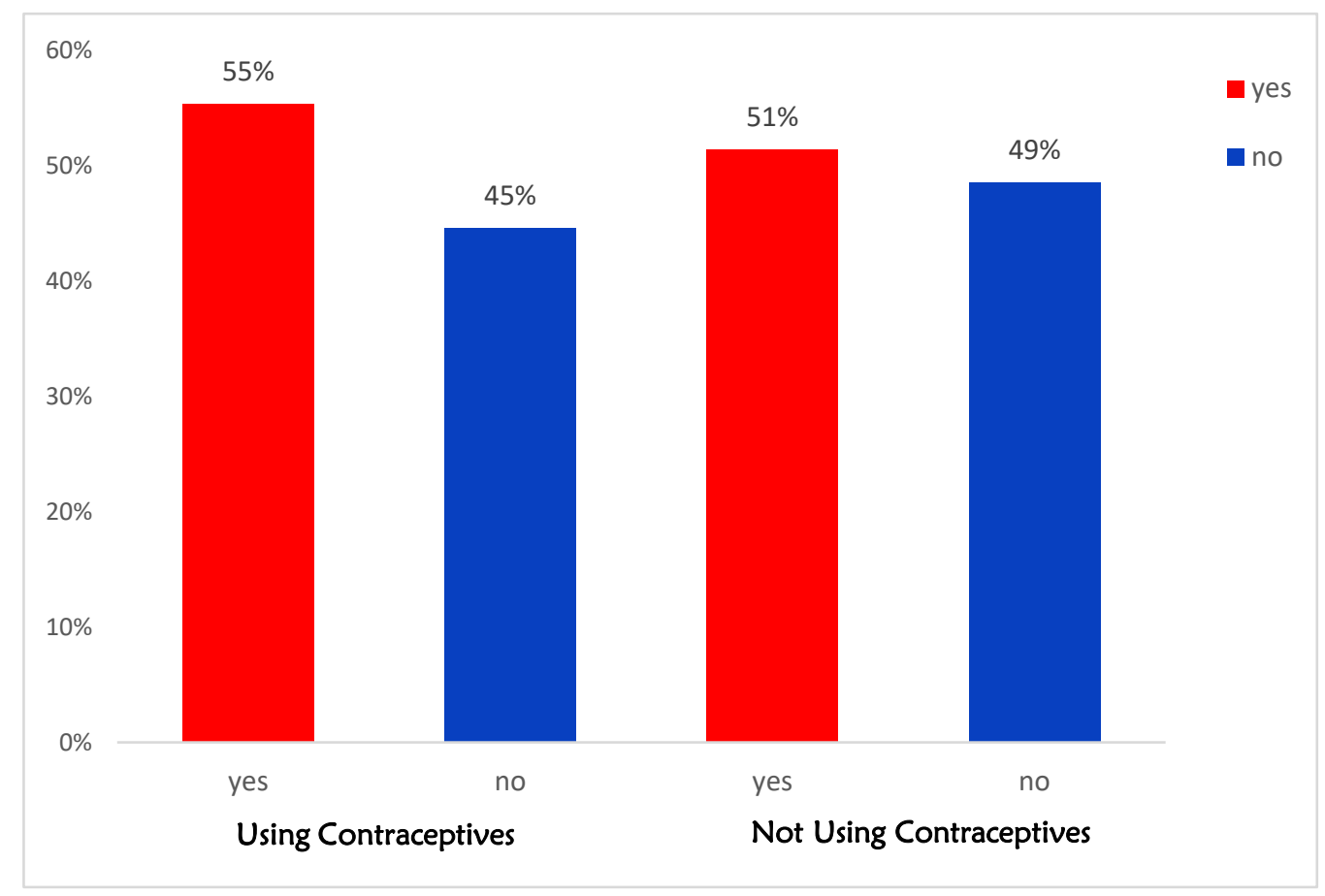

Figure 6. Heard Family Planning on the Radio.

Fifty-five percent of married women who were using contraceptives heard family planning announcements on the radio, while $45 \%$ did not. On the other hand, among the 35 married women who were not using contraceptives, $51 \%$ of them heard family planning on radio and $49 \%$ did not. 


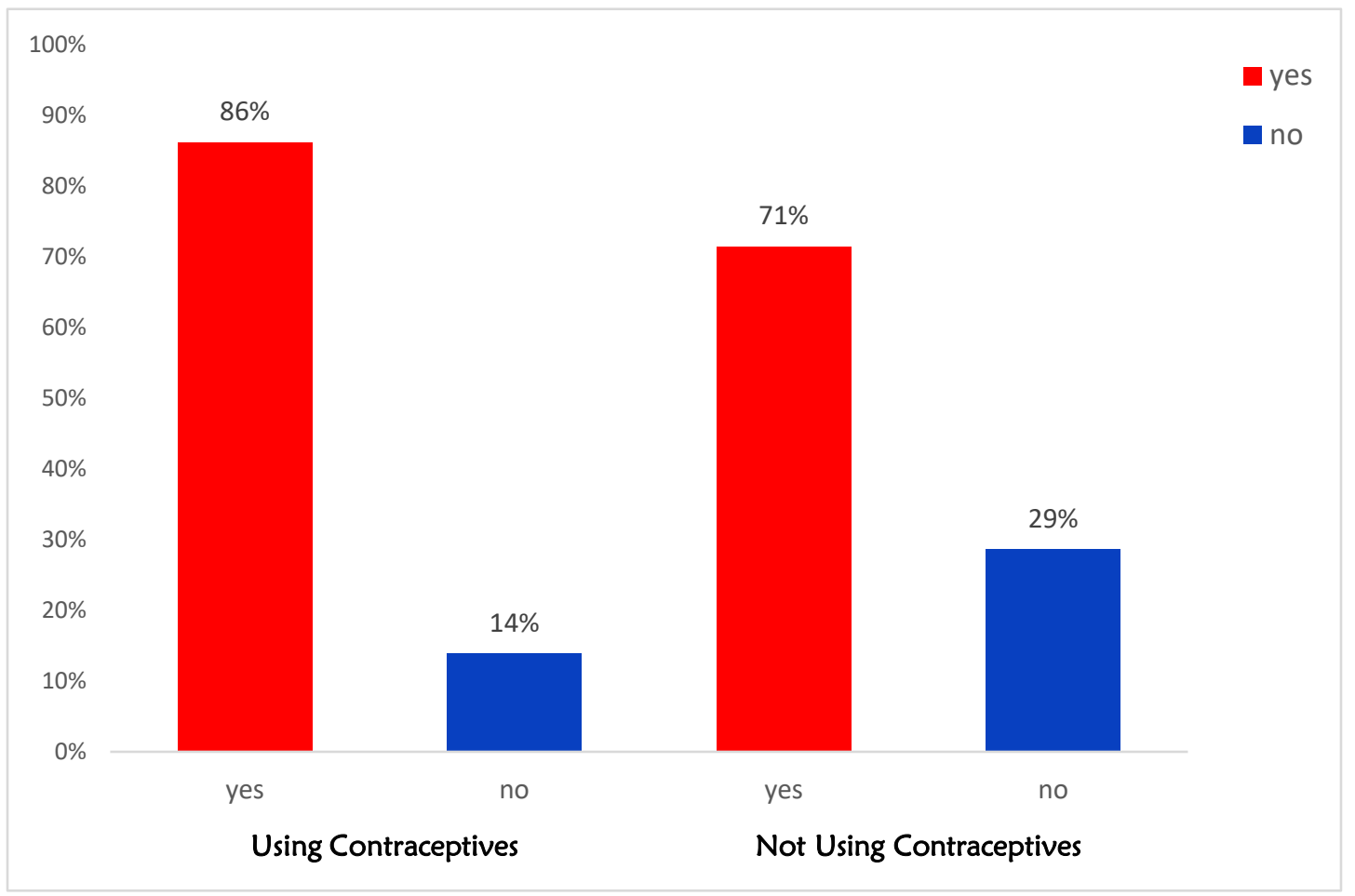

Figure 7. Heard Family Planning on the Television.

Eighty-six percent of married women who were using contraceptives heard family planning on their televisions, while $14 \%$ of them did not. Also, $71 \%$ who were not using contraceptives heard family planning announcements on their televisions, while $29 \%$ did not. 


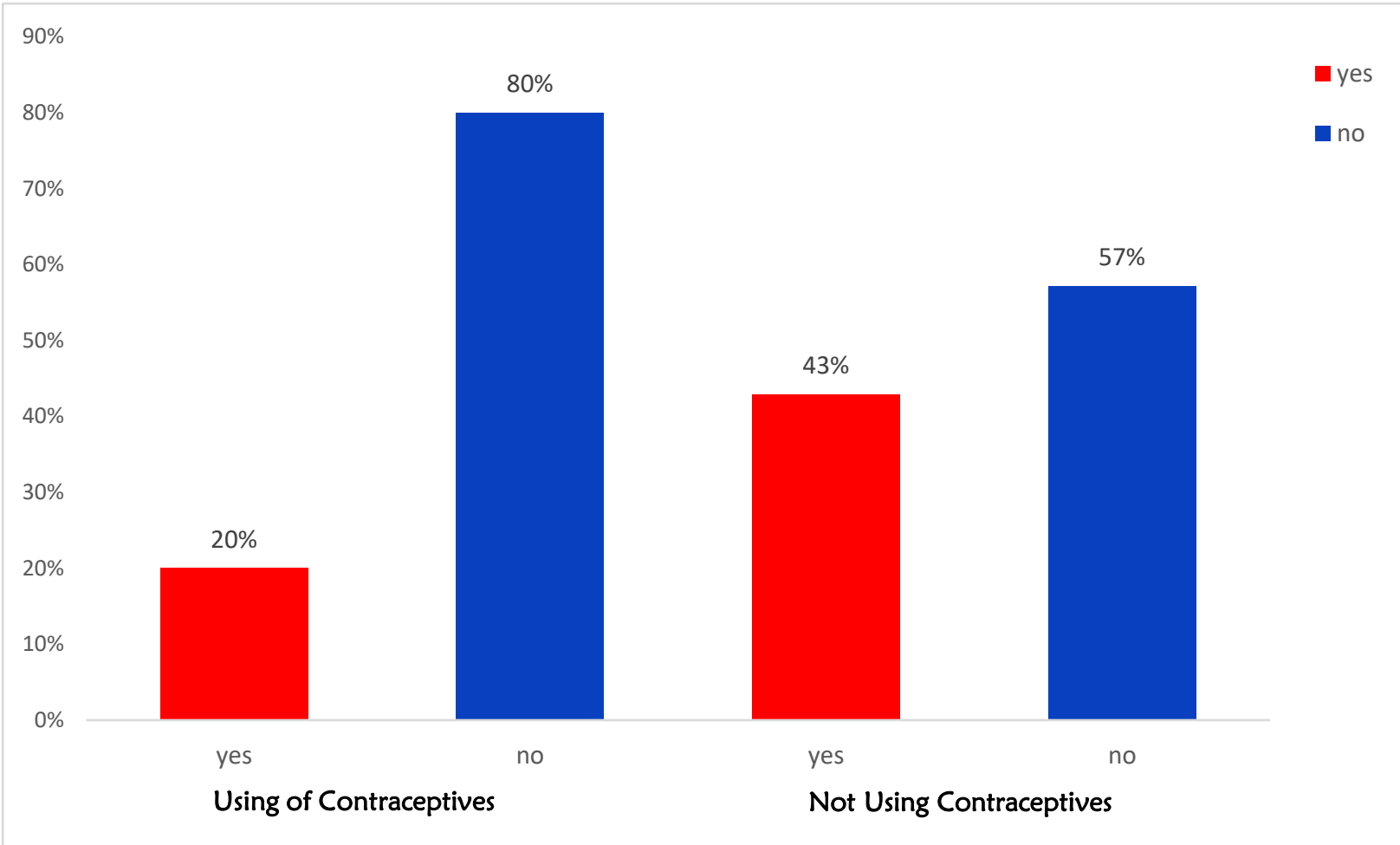

Figure 8. Read about Family Planning in the Newspaper.

Among 65 married women who were using contraceptives, 20\% of them read family planning in the newspaper, while $80 \%$ did not. Also, among 35 married women who were not using contraceptives, $43 \%$ of them read family planning in the newspaper, while $57 \%$ did not. 


\section{Significant Predictor Variables}

Table 3 shows the result of binary logistic regression using statistical software. It identifies the predictor models which are significant in making a mathematical model.

Table 3. Variables in the Equation

\begin{tabular}{|c|c|c|c|c|c|c|c|c|c|}
\hline & \multirow{2}{*}{ B } & \multirow{2}{*}{ S.E. } & \multirow{2}{*}{ Wald } & \multirow{2}{*}{ Df } & \multirow{2}{*}{ Sig. } & \multirow{2}{*}{$\operatorname{Exp}(B)$} & \multicolumn{2}{|c|}{$95 \%$ C.I.for $\operatorname{EXP}(B)$} \\
\hline & & & & & & & & Lower & Upper \\
\hline \multirow{11}{*}{ Step $1^{a}$} & Desire & -2.683 & .956 & 7.885 & 1 & .005 & .068 & .011 & .445 \\
\hline & Education & -1.087 & .789 & 1.896 & 1 & .169 & .337 & .072 & 1.585 \\
\hline & Religion & 1.258 & 478 & 6.936 & 1 & .008 & 3.518 & 1.380 & 8.973 \\
\hline & Work & -3.762 & 971 & 14.999 & 1 & .000 & .023 & .003 & .156 \\
\hline & Income & -.327 & .615 & .283 & 1 & .595 & .721 & .216 & 2.409 \\
\hline & Radio & -.161 & 1.335 & .014 & 1 & .904 & .852 & .062 & 11.649 \\
\hline & TV & 1.874 & 1.213 & 2.388 & 1 & .122 & 6.517 & .605 & 70.216 \\
\hline & Newspaper & -3.404 & 2.119 & 2.582 & 1 & .108 & .033 & .001 & 2.112 \\
\hline & ZAge & 198 & .421 & .220 & 1 & .639 & 1.219 & .534 & 2.782 \\
\hline & ZChildren & -.407 & .408 & .995 & 1 & .318 & .665 & .299 & 1.481 \\
\hline & Constant & 3.589 & 1.734 & 4.282 & 1 & .039 & 36.186 & & \\
\hline
\end{tabular}

a. Variable(s) entered on step 1: Desire, education, Religion, Work, income, Radio, TV, Newspaper, ZAge, ZChildren.

b. Significant at 0.05 level of significance. 
As presented in Table 3, the significant factors (the highlighted area) which affects the use of contraceptives among women are the "desire", "religion", and "employment status" with pvalues (Sig.) of $0.005,0.008$ and 0.000 , respectively. Thus, these factors will be considered in the formulation of the model.

Desire of having more children, religion, and employment status were the significant factors that were useful in predicting the contraceptive use among married women. The first factor, which is the desire of having more children, indicates that married women who were less likely to desire to have more children were more likely to use contraceptives. The second factor, from several studies have demonstrated that religion had a significant role in the use of contraceptive methods. A study by Molyneaux (1990) in Indonesia showed that religion played a major role in method use and choice. On the other hand, the effect of religion on contraceptive use was also observed in a study in Greater Freetown, Sierra Leone, by Amin (1992). They found a higher contraceptive prevalence rate among women affiliated with Catholicism or another Christian religion than among those affiliated with Islam (28 percent, 24 percent and 13 percent respectively). The lower use of contraceptives among Islam women was positively associated with the desire for more children. The third significant factor is employment status which can be supported by a study from Kinshasa, Kenya that stated "Self-employed women and employees had much higher predicted probabilities of contraceptive use". Another study conducted in Bangladesh revealed that the contraceptive use was found higher among employed women $(67 \%)$ than that of unemployed women.

The following are the factors that were not significant in predicting contraceptive use namely: educational attainment, family income per month, exposure to family planning information from mass media, age, and number of children. These factors in this study would not be useful in predicting the probablity of contraceptive use among married women. These findings might be influenced by the fact that the desire to have more children appear to have more influence in contraceptive use. No matter what their educational attainment is, their income or economic status, exposure to mass media, age, and number of children, they are more likely to use contraceptives given that they are not desirous of having more children. In this study, the desire for children, religion, and employment status were highly associated with contraceptive use.

\section{Development of a Model using Logistic Regression}

In Table 4, we have obtained the estimated coefficients (B) of the significant factors in using contraceptives.

Table 4. Estimated Coefficients of the Factor of Contraceptive use

\begin{tabular}{|l|c|}
\hline Independent Variables $\left(X_{i}\right)$ & Estimated Coefficients (B) \\
\hline Constant & 3.589 \\
\hline
\end{tabular}




\begin{tabular}{|l|c|}
$\left(X_{1}\right)$ Desiring of having more & \\
children? & -2.683 \\
\hline$\left(X_{3}\right)$ Religion & 1.258 \\
\hline$\left(X_{4}\right)$ Do you have a work? & -3.762 \\
\hline
\end{tabular}

A fitted model was first formulated to evaluate the performance of the proposed logistic regression model. The model is then formulated with sets of independent variables that would quantify the likelihood or odds of contraceptive use among married women. The interpretation in logistic regression is done by examining the odds of having positive response, odds $(\mathrm{Y}=1)$. From the definition of odds, odds $(Y=1)$, which is equivalent to:

$$
e^{(3.589-2.683 \text { desire }+1.258 \text { religion-3.762work })}
$$

The above result can be used in assessing the odds in using contraceptives. For instance, if we assume that the respondent had no desire of having more children (desire=0), a Catholic (religion=0), and is not employed (work=0), then the odds; $e^{(3.589-2.683(0)+1.258(0)-3.762(0))}=36.186$. So, having no desire, a Catholic, and is not employed have a 36.186 odd of using contraceptives. If our respondent had a desire of having more children (desire $=1$ ), a Protestant (religion=1), and is employed (work=1), then the odds; $e^{(3.589-2.683(1)+1.258(1)-3.762(1))}=0.202$.

The odds can be converted to probabilities using the following equation:

$$
\pi=\frac{e^{\left(3.589-2.683 X_{1}+1.258 X_{3}-3.762 X_{4}\right)}}{1+e^{\left(3.589-2.683 X_{1}+1.258 X_{3}-3.762 X_{4}\right)}}
$$

Using (1), the logistic regression model is:

$$
\operatorname{logit}(\pi)=\log \left(\frac{\pi}{1-\pi}\right)=3.589-2.683 X_{1}+1.258 X_{3}-3.762 X_{4}
$$


where $\pi$ : is the probability that contraceptive use is affected,

$x_{1}$ : the desire to have more children,

$x_{3}$ : religion, and

$x_{4}$ : employment status.

For instance, the probability for married woman with no desire of having more children, a catholic, and have no work is

$\pi=\frac{e^{\left(3.589-2.683 X_{1}+1.258 X_{3}-3.762 X_{4}\right)}}{1+e^{\left(3.589-2.683 X_{1}+1.258 X_{3}-3.762 X_{4}\right)}}=\frac{e^{(3.589-2.683(0)+1.258(0)-3.762(0))}}{1+e^{(3.589-2.683(0)+1.258(0)-3.762(0))}}=0.9731$.

It shows that a married woman has a probability of $97.31 \%$ of using contraceptives given no desire to have more children, is a Catholic, and has no work. On the other hand, for obtaining the probability for a married woman who has a desire to have more children, is a Protestant, and is working is

$$
\pi=\frac{e^{(3.589-2.683(1)+1.258(1)-3.762(1))}}{1+e^{(3.589-2.683(1)+1.258(1)-3.762(1))}}=0.1683
$$

It shows $16.83 \%$ probability of a married woman having a desire to have more children, is a Protestant, and has work, to use contraceptives.

\section{Hosmer and Lemeshow Test}

The Hosmer-Lemeshow test, a test of goodness-of-fit of the model was provided by the statistical software. This is one of the statistical measures that tell how good the model is based on its significance measure. If this measure's $p$-value is greater than 0.05 ( $p>0.05)$, then the Hosmer $\&$ Lemeshow test of the goodness of fit suggests the model is of good fit to the data.

Table 5: Hosmer and Lemeshow Test

\begin{tabular}{|c|c|c|c|}
\hline Step & Chi-square & df & Sig. \\
\hline 1 & 4.615 & 8 & .798 \\
\hline
\end{tabular}


Table 8 shows the observed test statistic. Since the p-value (sig.) of 0.798 is greater than the level of significance $\alpha=0.05$, then the model is a good fit to the data.

\section{Validation of the Model}

A re-survey was conducted to validate the model. The data gathered were substituted to the formulated model one by one.

$$
\pi=\frac{e^{\left(3.589-2.683 X_{1}+1.258 X_{3}-3.762 X_{4}\right)}}{1+e^{\left(3.589-2.683 X_{1}+1.258 X_{3}-3.762 X_{4}\right)}}
$$

Table 6: Validation Summary

\begin{tabular}{|cc|c|c|c|}
\hline \multirow{2}{*}{ Observed } & \multicolumn{3}{|c|}{ Predicted } \\
\cline { 3 - 4 } & \multicolumn{2}{|c|}{ Use_Contra } & Percentage \\
\cline { 3 - 4 } & No & 19 & 4 & 82.6 \\
\hline Use_Contra & Yes & 2 & 25 & 92.6 \\
& & & & 88.0 \\
\hline
\end{tabular}

Table 6 shows that 25 married women, that were predicted to use contraceptives, really did use. On the other hand, four married women that were predicted to use contraceptives were actually not using. Also, 19 married women who were predicted not using contraceptives were truly not using, while two married women who were predicted not using contraceptives were indeed using them.

In general, the columns are the two predicted values of the dependent, while the rows are the two observed (actual) values of the dependent variable. In this study, $92.6 \%$ were correctly classified in using contraceptives and $82.6 \%$ for not using. Overall $88.0 \%$ were correctly classified which implies that the formulated model is useful in predicting the probablity in using contraceptives among married women. 


\section{Summary, Conclusions and Recommendations}

This chapter presents the summary or the research work undertaken, the conclusions drawn, and the recommendations made as an outgrowth of this study.

\section{Summary}

As the population of the Philippines is growing at a rapid pace, raising awareness among people regarding family planning is very important. One of the best ways is to advise them about the various contraceptive methods that are available in order to avoid any unwanted pregnancies. In the country, contraceptives are available for people from all kinds of lifestyles and all kinds of plans. Whether you're single or married, whether you never want to have children or you want to have children come next year, one has his/her options. This study aims to determine the significant factors and formulate a model that could predict the probability of using contraceptives among married women in Cagayan de Oro City using binary logistic regression. From the results, only three of the ten factors were significant, namely: the desire to have more children, religion, and work, with p-values $0.005,0.008$, and 0.000 , respectively. The significant factors were considered in formulating the predicting model.

The performance of the formulated model was evaluated using Hosmer-Lemeshow (a statistical test for goodness-of-fit). Based on the result, the p-value of 0.798 which is greater than the significance level of 0.05 implies that the model is a good fit to the data.

\section{Conclusion}

Three out of ten factors, namely: the desire of having more children, religion, and employment status, were considered predictors of contraceptive use among married women in Cagayan de Oro City. The model that was formulated using the predictors was then used to validate the result (using the re-survey data). $92.6 \%$ were correctly classified in using contraceptives and $82.6 \%$ for not using. Overall $88.0 \%$ were correctly classified. Thus, having a high percentage implies that using those significant factors for the formulation of the model will be very useful in predicting the probablity of contraceptive use of a married woman.

\section{Recommendation}

The researcher recommends the following:

1. Consider other factors that might be significant in determining contraceptive use.

2. Expand the scope of the study (Area and Age).

3. Try other methods that will be useful in solving the problem. 


\section{References}

Adwere-Boamah, Joseph and Hufstedler, Shirley (2015). Predicting Social Trust with Binary Logistic Regression. Research in Higher Education Journal, v 27.

Amin, R., Jamir, C., and Robert B. (1992). Socioeconomic Differentials in Contraceptives Use and Desire for More Children in Greater Freetown, Sierra Leone. International Family Planning Perspectives, 18(1), pp 24-26.

Anguko, A.A (2014). Determinants of Contraceptive Use among Women of Reproductive Age in North Eastern Kenya. University of Naorobi.

Demographic and Health Survey Key Findings.

Germek (2012). Predicting Contraceptive Use among Women ate risk of Unintended Pregnancy. California State University, Sacramento.

Islam A, Mondal N, Khatun M, et al. Prevalence of determinants of contraceptive use among employed and unemployed women in Bangladesh. International Journal of $\mathrm{MCH}$ and AIDS.2016. 5(2):92-102.

Jennifer Frost and Laura Lindberg (2013). Reasons for using contraception: perspectives of US women seeking care at specialized family planning clinics. Guttmacher Institute.

Kidanekal et.al (2013). Degree Prediction Using Logistic Regression. Lund University, Sweden.

Molyneaux, J.W., Charles E. Leman, S.P. Pandi, and Trisno Soni (1990). Correlates of Contraceptive Method Choice in Indonesia and Sri Lanka. The Population Council, New York, USA

Muchabaiwa. (2013). Logistic Regression to Determine Significant Factors Associated with Share Price Change. University of South Africa.

Niculescu, G. (2015). Impact of Contraceptive Methods on Female Fertility. University of Medicine and Pharmacy of Craiova.

Philippines National Demographic and Health Survey (NDHS) (2013). 2013 National

Philippine Statistics Authority (2013). Contraceptive Use Among Filipino Women (Based from the Results of the 2011 Family Health Survey). 
Sekhara Reddy, et al. (2015). Binary Logistic Regression Analysis in Assessing and Identifying Factors that Influence the Use of Family Planning: The Case of Ambo Town, Ethiopia.

International Journal of Modern Chemistry and Applied Science 2015, 2(2), 108-120.

Shapiro David and B. Oleko Tambashe. (1994). The Impact of Women's Employment and Education on Contraceptive use and Abortion in Kinshasa, Zaire. Studies in Family Planning, 25(2), pp 96-110.

Teresa Castro Martín and Fatima Juárez (1995). The Impact of Women's Education on Fertility In Latin America: Searching for Explanations. Guttmacher Institute.

World Health Organization (WHO) (2017). Family Planning/Contraception. Zohirul, et al. (2016). Prevalence and Determinants of Contraceptive use among Employed and Unemployed Women in Bangladesh. 